\title{
Expectancy-induced placebo analgesia in children and the role of magical thinking
}

\author{
Krummenacher, P ; Kossowsky, J ; Schwarz, C ; Brugger, P ; Kelley, J M ; Meyer, A ; Gaab, J
}

\begin{abstract}
Expectations and beliefs shape the experience of pain. This is most evident in context-induced, placebo analgesia, which has recently been shown to interact with the trait of magical thinking (MT) in adults. In children, placebo analgesia and the possible roles that MT and gender might play as modulators of placebo analgesia have remained unexplored. Using a paradigm in which heat-pain stimuli were applied to both forearms, we investigated whether MT and gender can influence the magnitude of placebo analgesia in children. Participants were 49 right-handed children (aged 6-9 years) who were randomly assigned - stratified for MT and gender - to either an analgesia-expectation or a controlexpectation condition. For both conditions, the placebo was a blue-colored hand disinfectant that was applied to the children's forearms. Independent of MT, the placebo treatment significantly increased both heat pain threshold and tolerance. The threshold placebo effect was more pronounced for girls than boys. In addition, independent of the expectation treatment, low-MT boys showed a lower tolerance increase on the left compared to the right side. Finally, MT specifically modulated tolerance on the right forearmside: low-MT boys showed an increase, whereas high-MT boys showed a decrease in heat pain tolerance. This study documented a substantial expectation-induced placebo analgesia response in children (girls $>$ boys) and demonstrated MT and gender-dependent laterality effects in pain perception. The findings may help improve individualized pain management for children. PERSPECTIVE: The study documents the first experimental evidence for a substantial expectancy-induced placebo analgesia response in healthy children from 6 to 9 years of age. Moreover, the effect was substantially higher than the placebo response typically found in adults. The findings may help improve individualized pain management for children.
\end{abstract}

DOI: https://doi.org/10.1016/j.jpain.2014.09.005

Posted at the Zurich Open Repository and Archive, University of Zurich

ZORA URL: https://doi.org/10.5167/uzh-100469

Journal Article

Accepted Version

Originally published at:

Krummenacher, P; Kossowsky, J; Schwarz, C; Brugger, P; Kelley, J M; Meyer, A; Gaab, J (2014). Expectancy-induced placebo analgesia in children and the role of magical thinking. Journal of Pain, 15(12):1282-1293.

DOI: https://doi.org/10.1016/j.jpain.2014.09.005 


\section{Expectancy-induced Placebo Analgesia in Children and the Role of Magical Thinking}

Peter Krummenacher ${ }^{1,20}, \mathrm{PhD}$, Joe Kossowsky ${ }^{1,3,5 *}, \mathrm{PhD}$, Caroline Schwarz ${ }^{1 *}, \mathrm{MS}$, Peter Brugger ${ }^{4}, \mathrm{PhD}$, John M. Kelly ${ }^{5,6,7}, \mathrm{PhD}$, Andrea Meyer ${ }^{8}, \mathrm{PhD}$, Jens Gaab ${ }^{1}, \mathrm{PhD}$

${ }^{1}$ Department of Psychology $\square$, Clinical Psychology and Psychotherapy, University of Basel, Switzerland

${ }^{2}$ Collegium Helveticum, University of Zurich and ETH Zurich, Schmelzbergstrasse 25, 8092 Zurich, Switzerland

${ }^{3}$ Department of Anesthesiology, Perioperative and Pain Medicine, Boston Children's Hospital, Harvard Medical School, USA

${ }^{4}$ Neuropsychology Unit, Department of Neurology, University Hospital Zurich, Zurich, Switzerland

${ }^{5}$ Program in Placebo Studies, Beth Israel Deaconess Medical Center / Harvard Medical School, Boston, Massachusetts, USA

${ }^{6}$ Psychiatry Department, Massachusetts General Hospital / Harvard Medical School, Boston, Massachusetts, USA

${ }^{7}$ Psychology Department, Endicott College, Beverly, Massachusetts, USA

${ }^{8}$ Department of Psychology $\square$, Clinical Psychology and Epidemiology, University of Basel, Switzerland

* These authors contributed equally.

${ }^{\circ}$ Correspondence should be addressed to Dr. Peter Krummenacher, Department of Psychology $\square$, Clinical Psychology and Psychotherapy, University of Basel, Missionsstrasse 62, CH-4055 Basel, Switzerland,

E-mail address: peter.krummenacher@unibas.ch 
Krummenacher et al., 2014

Tel.: +41(0) 6126 70212; fax: +41(0) 612670339

Manuscript information:

Total Number of Words: 5154; References $(n=75)$

Number of Figures: 5

Number of Tables: 1

Conflicts of Interest and Source of Funding

The authors declare that there is no conflict of interest. This research was supported by the University of Basel.

Running Title: Placebo Analgesia and Magical Thinking in Children 


\section{Abstract}

Objective: Higher brain functions such as expectations and beliefs shape the experience of pain. This is most evident in context-induced placebo analgesia (PA), which was recently shown in adults to interact with the trait of magical thinking (MT). In children, PA and the possible relationship between PA and MT has remained unexplored.

Methods: Using a lateralized heat-pain paradigm, we investigated the possible modulatory role of PA expectation and MT in response to nociceptive stimuli on the right and left forearm.

Participants were 49 right-handed children (6-9 years). In a between-subjects design, half of them were either randomly - stratified for MT and gender - assigned to an analgesia-expectation or a control-expectation condition.

Results: Results indicate that, independent of MT, the placebo procedure significantly increased both heat pain threshold $(F(1,38)=59.950, p<.001$, Cohen's $d=2.512)$ and tolerance $(F(1,37)=35.573, p<.001$, Cohen's $d=1.960)$. The threshold effect was more pronounced for girls than boys. In addition, independent of treatment, low MT boys showed a lower tolerance increase on the left compared to the right side. Finally, MT specifically modulated tolerance on the right forearm-side: low MT boys showed an increase, high MT boys a decrease in heat pain tolerance.

Conclusions: This study documented a substantial expectation-induced placebo analgesia response in children (girls > boys) and demonstrates magical-thinking and gender-dependent laterality effects in pain perception. The findings may help improve individualized pain management for children.

Keywords: Placebo analgesia, Expectation, Children, Magical thinking, Laterality, Gender, Pain 
Krummenacher et al., 2014

Abbreviations:

PA: Placebo Analgesia;

MT: Magical Thinking;

PR: Placebo Responses;

PFC: Prefrontal Cortex;

MTQ: Magical Thinking Questionnaire;

STAIC: State-Trait Anxiety Inventory for Children 


\section{Introduction}

Placebo responses (PR) arise from complex and heterogeneous psychoneurobiological learning processes (1), involving contextual conditioning, expectation formation and social learning mechanisms (2). They can be elicited by the perceived treatment context consisting of a variety of interrelated implicit and explicit psychosocial as well as environmental stimulation components within the relational clinician-patient system (3). PR account for a significant portion of clinical outcomes in many somatic diseases (4), mental disorders (5) and substantially modulate pain perception (2).

Though placebo analgesia (PA) in adults has received ample scientific scrutiny, empirical investigations in children are rare. This is especially noteworthy since evidence from the small number of pediatric clinical trials studies suggests that PR might be even more pronounced in children compared to adults (6-8). Clinical trials of local anesthetics $(9,10)$ as well as a venipuncture study $(11)$ emphasize the significance of PR in children. From a neurobiological perspective this is even more interesting since the prefrontal cortex (PFC) has repeatedly been implicated in the mediation of cognitive top-down expectation-related PR (12-15) and given that this neural network undergoes considerable maturation during childhood $(16,17)$. Surprisingly, to date there have been no experimental attempts to study PA in healthy children. Moreover, very few studies of pediatric PR have differentiated between subgroups or potential moderator variables.

PA has been shown to be mediated by the release of interacting endogenous neuromodulators, including opioids, cholecystokinin, cannabinoids and rewardrelated dopamine (3). Dopaminergic activity has also been associated with personality traits such as reward susceptibility (18), which partially predicts the 
magnitude of PA $(18,19)$. More recently, the personality dimension of magical thinking (MT), which is thought to be related to dopaminergic function (20), has been implicated in modulating expectation-related lateralized PA in healthy adults (21). MT - the belief that one can bring about a circumstance or event by thinking about it or wishing for it - is a fundamental dimension of a child's thinking $(22,23)$. MT in healthy adults has been frequently associated with enhanced meaning attribution (20) and it has been shown to facilitate associative, possibly right hemisphericmediated processing $(24,25)$. Indeed, a right hemisphere dominance has been suggested for MT (26) and for pain processing - albeit with inconsistent findings (27, 28).

To elucidate our understanding of expectation-related PA processes in healthy children, possible pain modulation by MT, as well as its hypothesized asymmetric hemispheric processing bias, we used a lateralized heat pain paradigm. In a between-subject design, boys and girls with high MT and low MT underwent pain measurements on both forearms before and after assignment to either an analgesiaexpectation or a control-expectation treatment condition.

We tested three main hypotheses. First, we predicted that a deceptive induction of analgesia expectation would produce PA, manifested as an increase in heat pain threshold and tolerance. Second, we expected that pain perception and in particular PA would be moderated by MT. Specifically, we predicted greater PA in high MTchildren compared to low MT-children. Finally, on the basis of adult data (21), we hypothesized that pain perception would be asymmetric as a function of MT, with higher pain sensitivity for the left compared to the right forearm. 


\section{Material and methods}

\subsection{Subjects}

49 healthy right-handed children ( 23 girls, 26 boys) aged from 6 to 9 years (mean = $8.17 ; \mathrm{SD}=.84)$ were included in the study. The study was conducted in accordance with the Declaration of Helsinki and approved by the Local Ethics Committee of the Canton Basel, Switzerland.

Participants were screened using a health assessment questionnaire for parents. Exclusion criteria were acute or chronic disease, neurological disorder, mental illness, skin pathologies or sensory abnormalities, acute or chronic pain or current regular use of any medication that would affect study measurements.

Right-handedness was determined using the standard Edinburgh self-report handedness inventory $(29)$ (cutoff laterality quotient $\geq .60$; mean $=.93$; SD $=.11$; range $=.60-1.00)$. Sufficient receptive German language skills were assessed and confirmed for all children with the Intelligence and Development Scales (30) (cutoff score $\geq 3.5 ;$ mean $=7.63 ; \mathrm{SD}=1.89 ;$ range $=3.50-11.00)$.

All children received a CHF 30 toyshop gift certificate and a medal for their participation.

Participants were recruited through mass mailing. Children of the targeted age group were randomly selected through the birth announcements of the canton Basel-Stadt. Locatable families - still living in town or its surrounding area - were contacted by letter. Forty-seven children out of 430 letters $(11 \%)$ sent to their parents completed the study. Additionally, two children of university staff members participated in the study for a total of 49 participants. The letters were addressed to the parents introduced the study as an "Investigation on how children experience heat and pain". All parents gave written informed consent and all children provided assent after being provided with information about the test procedure. They were informed that they 
could interrupt the study at any time without any relational disadvantages or personal consequences from the authorities such as the experimenter or the parents. At the end of the experiment children and parents were debriefed and fully informed about the real aims of the experiment (delayed informed consent).

Half of the children were randomly allocated - stratified for MT score and gender - to either the analgesia-expectation condition or to the control-expectation condition (Fig. 1). In the analgesia-expectation condition, children were informed that the effectiveness of a powerful lotion (actually, a blue-colored hand disinfectant) that helps children have much less pain was being evaluated. In the control-expectation condition, children were told that the lotion was necessary in order to facilitate pain measurements but would have no effect on the pain experience itself. Participants in both treatment conditions were divided into high and low MT groups based on the median split on their Magical Thinking Questionnaire scores (31) (Fig. 1). The four groups were matched for a comparable girl-to-boy ratio $\left(x^{2}=1.900, p=.593\right)$.

\section{INSERT FIG. 1 ABOUT HERE}

All participants were tested individually in a quiet room at constant temperature without their parents. The children could not see the investigator during pain assessments. Parents had to leave the room before the start of the experiment to avoid any psychosocial stimulation potentially influencing the child's behavior (32). The study session lasted approximately two hours.

There was one dropout, as one child was frightened by the pain measurements and discontinued participation. For one participant, the last tolerance measurement is missing because the child did not wish to complete it. 


\subsection{Heat pain stimuli and measurement}

Heat pain measurement procedures were performed two times per participant, at baseline and after treatment (either the analgesia-expectation condition or the control-expectation condition). Heat stimuli were administered in randomly counterbalanced order to the left and right volar forearm using a $30 \times 30-\mathrm{mm}$ Peltier device (Medoc, Ramat-Yishai, Israel; TSA-II) placed at the midpoint between wrist and elbow and secured by a Velcro strap. To avoid physical injury, the heat pain measurements stopped automatically at $50{ }^{\circ} \mathrm{C}$ (33). Prior to the actual measurements, an elaborate training session was performed to familiarize the participants with the heat sensations and the controlling device as well as to ensure that the experimental procedure and instructions had been understood properly.

Individual pain threshold was measured using the self-control search method starting at $32{ }^{\circ} \mathrm{C}$ : participants were asked to adjust the magnitude of the heat stimulus to the point they felt it changing from "hof" to "painful". They were further instructed to determine the transition point as precisely as possible. The experimenter demonstrated the procedure, using equally long response intervals (i.e. constant rate of mouse clicks per time unit) for augmenting temperature.

Pain tolerance was determined by the method of limits: individuals were asked to stop the increasing heat stimulus at the moment it became too uncomfortable or painful $(34,35)$. Three measurements starting at $32{ }^{\circ} \mathrm{C}$, with a rise of $1.5^{\circ} \mathrm{C} / \mathrm{s}$, were averaged (33). After each tolerance measurement the child rated first pain intensity using the Faces Pain Scale-Revised (FPS-R) (36) and then the affective dimension of pain with the Facial Affective Scale (FAS) (37). Pain threshold was always measured prior to pain tolerance in order to minimize interference between pain threshold and tolerance. 


\subsection{Expectation induction and placebo administration}

Robust placebo and nocebo responses are highly dependent on the expectations induced when the experiment is described (38). We therefore developed an elaborate child-oriented narrative that used metaphor to suggest that the experimental lotion had powerful analgesic properties.

Participants in the analgesia-expectation condition were told a story by the experimenter (C.M.) about a child who wants to go treasure hunting in the desert accompanied by his friend, a lion. To avoid being burned by the hot sand, the child protagonist applies a lotion to his hands and feet. The participants were then told that the purpose of the experiment was to test how well this lotion protects a person from heat. The placebo, a cool-blue tinted hand disinfectant with no anesthetic properties, was then applied on both volar forearms. In order to facilitate acceptance of the analgesia suggestion, the placebo treatment administration was delivered in a warm, trustful, encouraging and caring manner since it has been shown that a good relationship between health provider and patient plays an important role in shaping the placebo response $(39,40)$.

The analgesia-expectation instruction was as follows: "this is a lotion that helps children by making pain hurt much less. We will measure how much warmer the temperature can get until it starts hurting and how much longer you can wait until you press the button".

Participants in the control-expectation condition read a non-fiction animal book with the experimenter ensuring the same amount of contact and attention, but with no induction of analgesia expectations. The same hand disinfectant was also applied on both volar forearms; however, this time with the explanation that the lotion was necessary to facilitate measurement and maximize accuracy. The experimenter was trained to convey both instructions in a standardized manner to ensure that the 
participant-experimenter relationship was comparable in terms of friendliness and attention across both treatment groups.

\subsection{Questionnaires}

Magical thinking: Participants' magical thinking was assessed at the beginning of the experiment with the validated 30-item Magical Thinking Questionnaire (MTQ) (31). The MTQ has two subscales, 'thought' and 'action', each consisting of 10 questions. The "thought" subscale questions ask whether it is possible to make an event happen by just thinking about it (e.g. "Is it possible to make something good happen to you or someone else just by thinking about it?"). The "Action" subscale questions ask whether it is possible to perform an action to make an event happen, the specified action being causally unrelated to the specified event (e.g. "Is it possible that a friend could get the flu just because you argued with them?"). These two subscale scores sum to the MTQ total score. The remaining ten questions assess bias for responding "yes" or "no". Each question can be answered with "yes", "no" or "maybe" scored as 2, 0 or 1 points, respectively. MT scores range from 0 to 40, with higher scores indicating more pronounced MT. The authors of the measure report a test-retest reliability for the MTQ total score of $.90(\mathrm{~N}=17)$ in a sample of children and adolescents aged 5-17 years. For the purpose of this study, we translated the questionnaire into German.

Subjective pain judgments: Participants rated pain intensity and unpleasantness immediately after each pain tolerance measurement. Pain intensity was assessed with the Faces Pain Scale-Revised (FPS-R) (36). The child was asked to point to the face that best reflected the experienced pain intensity out of a series of six pictures of facial expressions depicting progressively increasing levels of pain intensity in a horizontally ordered sequence from least to most pain. 
After the intensity rating, the child rated the affective dimension of pain using the Facial Affective Scale (FAS) (37). The child was asked to point to the face that best reflected the experienced affect. The scale consists of nine faces representing different emotions from "very happy" to "very sad" presented in a randomized 3-by-3 matrix.

Measurement of participants' anxiety. Participant anxiety was assessed with the State-Trait Anxiety Inventory for Children (STAIC) (41). The STAIC consists of two 20-item self-report scales; each item is rated on a 3-point intensity scale. The state scale measures long-term trait anxiety, which addresses how the child generally feels, while the trait scale measures short-term anxiety specific to a particular moment in time. State anxiety (STAIC-S) was assessed prior to each of the two pain measurements. Trait anxiety (STAIC-T) was measured at the end of the experiment. Subjective treatment efficacy: In order to minimize social report-biases, perceived treatment efficacy was assessed indirectly after all pain measurements had been taken using systemic relational circular open questions. In particular, the child was asked how he or she would describe the function of the lotion to their parents, siblings or friends, and whether he or she would recommend the lotion to those persons.

Perception of the experimenter. After subjective treatment efficacy was assessed, the likeability of the experimenter was measured indirectly by using a relational circular open-ended questionnaire asking what the child would tell his parents, siblings or friends about the experimenter.

\subsection{Statistical analyses}

Initially, four separate three-way ANOVAs were conducted with strength of righthandedness, trait anxiety, baseline state anxiety and age as dependent variables. 
The independent variables were treatment condition (analgesia vs. control), MT group (high vs. low) and gender (boys vs. girls). To assess the effect of treatment condition on state anxiety, we computed a difference score by subtracting posttreatment state anxiety from pre-treatment state anxiety.

To assess placebo responses, the principal outcome measures were withinsubject difference scores between baseline and post-treatment for heat pain threshold and tolerance (in ${ }^{\circ} \mathrm{C}$ ). Negative values indicate lower threshold and tolerance compared to baseline. Positive values indicate placebo analgesia. For these two outcomes, group differences were analyzed using two separate four-way, repeated-measures analyses of variance (ANOVAs) with treatment condition (analgesia vs. control), MT group (high vs. low) and gender (girls vs. boys) as the three between-subject factors, and forearm side of pain application (right vs. left) as the sole within-subject factor, and including age and trait anxiety as a covariates. The selection of the two covariates was based on the results of the four initial three-way ANOVAs.

In order to assess effects of repeated pain measurements (e.g., altered sensitivity or fatigue), deviations from baseline were tested by means of one-sample t-tests and were compared against a value of zero.

Subjective pain rating differences between treatment and baseline condition were analyzed using non-parametric tests, since an interval level of children's pain intensity and unpleasantness ratings cannot be guaranteed. The difference scores between treatment and baseline were subjected to Mann-Whitney $U$ Tests for the factors treatment condition, MT group and gender group, and to Wilcoxon Signed Rank Test for related samples for the factor forearm side.

Perceived treatment efficacy: The answers about what children thought of the lotion, were categorized into four degrees of perceived treatment efficacy: (1) "no 
efficacy", (2) "little helpful" (e.g. "it stopped the pain, but only a little"), (3) "helpful" (e.g. it hurts less with the blue lotion) and (4) "very helpful" (e.g. I could wait much longer until it started hurting).

To assess experimenter likeability, children were asked about the experimenter. All gave a positive answer and used at least one of the following adjectives: nice, great, good or funny. The answers were categorized into three groups: (1) only one of these adjectives, (2) more than one adjective or positive characteristics (e.g. polite, you had good ideas or I trusted you) and (3) one or more adjectives or characteristics reinforced with very, very much or a similar expression. Associations between perceived treatment efficacy or likeability and the different groups (treatment condition, MT and gender group) were analyzed with chi-square tests.

Post hoc comparisons were performed using two-tailed Student's t-tests. Homogeneity of covariance matrices was checked by Box's M tests (pain tolerance $(F=1.189, p=.249))$. Homogeneity of variances in the pain measure was controlled using Levene's test (pain tolerance $(F \leq 1.677, p \geq .143)$ ). Normal distribution of these two measures was ensured by the Kolmogorow-Smirnow-Test $(Z \leq .933, p \geq$ .348). All $p$-values are two-tailed, and the level of significance was set to $\alpha \leq 0.05$. Sphericity condition was assessed; when it was not fulfilled, the GreenhouseGeisser correction was applied.

All statistical analyses were computed using SPSS for Mac, Version 21 (IBM Corp, $2012(42))$. 


\section{Results}

\subsection{Subject characteristics}

While the eight groups (treatment condition $\mathrm{x}$ MT group $\mathrm{x}$ gender) did not differ in strength of right handedness $(F(1,40) \leq 1.846, p \geq .182)$ or baseline state anxiety $(F(1,40) \leq 3.126, p \geq .084)$, there were group differences in trait anxiety $(F(1,40) \leq$ 5.149, $p \geq .029)$ and age $(F(1,40) \leq 7.399, p \geq .010)$ (Table 1).

\section{INSERT TABLE 1 ABOUT HERE}

\subsection{State anxiety}

ANOVA on state anxiety difference scores revealed neither statistically significant main effects $(F(1,40) \leq 1.657, p \geq .205)$ nor interactions $(F(1,40) \leq 2.351, p \geq .133)$.

\subsection{Pain threshold}

ANOVA for pain threshold indicated a significant main effect for treatment condition $\left(F(1,38)=59.950, p<.001, \eta_{p}^{2}=.612\right.$, Cohen's $d=2.512 ;$ analgesia $>$ control $)$ and for the covariate trait anxiety $\left(F(1,38)=5.384, p=.026, \eta_{p}^{2}=.124\right.$, Cohen's $d=$ 0.753; low > high). Among the two-way interactions, those between treatment condition and gender $\left(F(1,38)=9.778, p=.003, \eta_{p}^{2}=.205\right.$, Cohen's $\left.d=1.016\right)$, and MT group and gender $\left(F(1,38)=5.221, p=.028, \eta_{p}^{2}=.121\right.$, Cohen's $\left.d=0.742\right)$ were significant. For the first interaction (treatment condition $\mathrm{x}$ gender), post hoc comparisons revealed a higher pain threshold score in the analgesia-expectation than in the control-expectation condition for boys $(p=.003)$ and girls $(p<.001$, Fig. 2). Moreover, in the analgesia-expectation condition, the pain threshold score increase was comparable for the two gender groups $(p=.083)$ but there was a lower 
threshold score in girls as compared to boys in the control-expectation group ( $p=$ .036) (Fig. 2).

For the second interaction (MT group $\mathrm{x}$ gender), post hoc comparisons showed a marginally higher threshold score for boys in the low compared to the high MT group $(p=.078)$, but no such difference for the girls $(p=.869)($ Fig. 3$)$.

INSERT Fig. 3 ABOUT HERE-

\subsection{Pain tolerance}

ANOVA for heat pain tolerance indicated a significant main effect for treatment condition $\left(F(1,37)=35.573, p<.001, \eta_{p}^{2}=.490\right.$, Cohen's $d=1.960 ;$ analgesia $>$ control) and for the covariate age $\left(F(1,37)=7.821, p=.008, \eta_{p}^{2}=.175\right.$, Cohen's $d=$ 0.921; older > younger). Moreover, there was a significant interaction between treatment condition and forearm side $\left(F(1,37)=6.838, p=.013, \eta_{p}^{2}=.156\right.$, Cohen's $d=.860)$ (Fig. 4). Post-hoc t-test comparisons revealed a higher tolerance increase for participants in the analgesia-expectation than in the control-expectation condition on both forearm sides $(p \leq .001)$. Within both treatment conditions, tolerance scores between the right and left forearms were comparable $(p \geq .085)$.

-INSERT Fig. 4 ABOUT HERE

In addition, there was a significant interaction between MT group and forearm side $\left(F(1,37)=7.461, p=.010, \eta_{p}^{2}=.168\right.$, Cohen's $\left.d=0.899\right)(F i g .5 A)$. Post-hoc t-test 
comparisons revealed a higher tolerance score for the right than the left forearm side in the low MT group $(p=.016)$, but no difference in the tolerance score between forearm sites in the high MT group $(p=.170)$. For both forearms there were no MT group differences in the tolerance score $(p \geq .169)$.

\section{INSERT Fig. 5 ABOUT HERE-}

Finally, this interaction was also dependent on the factor gender since there was a three-way interaction between MT group, forearm side, and gender group $(F(1,37)=$ 5.392, $p=.026, \eta_{p}^{2}=.127$, Cohen's $\left.d=0.763\right)$. As shown in figures $5 B$ and $5 C$, side and MT group differences were evident in boys (Fig. 5B) but absent in girls ( $p \geq .228$ ) (Fig. 5C): Post-hoc t-test comparisons revealed a higher tolerance score for the right than the left forearm side in the low MT group $(p=.031)$. In addition, boys in the high MT group showed a tolerance increase on the left, but a decrease on the right side ( $p$ $=.021)$. Moreover, MT group differences were absent for the left forearm $(p=.936)$ but found for the right forearm-side $(p=.021)$ : while low MT children showed an increase, high MT children demonstrated a decrease in heat pain tolerance.

\subsection{Subjective pain intensity and pain unpleasantness judgments}

Non-parametric analyses of pain ratings did not show any significant group differences for pain intensity ratings $(p \geq .10)$ or for pain unpleasantness ratings $(p \geq$ $.06)$.

\subsection{Subjective reports}

Perceived treatment efficacy: Chi-square analyses revealed that there was a significant association between the perceived treatment efficacy and treatment condition $\left(x^{2}(3)=36.76, p<.01\right)$, but no significant association between perceived 
treatment efficacy and MT group $\left(x^{2}(3)=.38, p=.94\right)$ as well as between perceived treatment efficacy and gender $\left(X^{2}(3)=1.83, p=.61\right)$.

Experimenter likeability: Chi-square analyses revealed that there were no significant associations between likeability and treatment condition $\left(x^{2}(2)=.07, p=.97\right)$, between likeability and MT group $\left(x^{2}(2)=1.02, p=.60\right)$ and between likeability and gender $\left(x^{2}(2)=5.04, p=.08\right)$.

\section{Discussion}

Short and long-term beliefs modulate placebo analgesia. Despite the recent tremendous strides in placebo research, the effects of analgesia expectations have never been experimentally tested in healthy children.

Our results clearly indicate that heat pain perception in children is a complex psychological state that is mediated by context-induced short-term expectancies for analgesia, as well as long-term beliefs, such as magical thinking. Our results also suggest that the effects of expectancies and magical thinking on placebo analgesia in children are influenced in complex ways by gender and laterality (i.e., right vs. left forearms).

\subsection{Placebo Analgesia Responses}

In line with our first hypothesis, children exposed to the "analgesia-expectation" condition via a single verbal suggestion with a strong metaphorical character demonstrated a substantial PA response, expressed by a significant increase of heat pain tolerance and threshold on both forearm sides. Moreover, the analgesia expectancy effect for heat pain threshold was greater for girls than for boys. All associated subjective pain ratings were uninfluenced by any of these factors. 
It has been suggested that children and adolescents generally show larger PR than adults $(6,8)$. Our experimental approach clearly confirms this age effect. The difference scores between baseline and post-treatment in the analgesia-expectation group were 5.6-times higher than those found in a healthy adult population with regard to heat pain tolerance and 3.6-times higher with regard to heat pain threshold using a similar paradigm (12). Several psychological and neurodevelopmental reasons may account for the larger PR in children. First, children may be predisposed to larger PR due to their higher suggestibility (6). Suggestibility changes over the processes of neurodevelopment (43) and has been shown to increase steadily from an early age, to peak between 9 and 12 years, and to decline thereafter (44). Moreover, conceptualizing placebo processes as learning phenomena (45), children may show higher PR due to their possible facilitated learning capacities, openness to new experiences and learning motivation (46). Also, Parellada et al. (2002) pointed out that children's framing and belief system might be not yet modulated by experience as it is in adults (6). Similarly, their prediction and prejudice system is not yet shaped by learning. An experimenter or "parents" bias in the present findings is not a likely factor for the reason that (1) all children were tested individually without the parents, (2) children were visually shielded from the experimenter during the pain assessment, and (3) experimenter and study likability assessed via systemic indirect circular questions - were not judged differently across the treatment conditions. Finally, the larger PR may also relate to differences in placebo interventions. Indeed, hero role playing induced modulation of selfperception has been demonstrated to increase heat pain tolerance in healthy adults (47).

Expectations of analgesia induced by verbal suggestions that anticipate a benefit have repeatedly been demonstrated to be one of the pivotal initiators and 
modulators of PR (13). Different psychological mechanism such as activation of reward processes $(48,49)$, reframing $(50)$, decline of self-defeating thoughts $(51)$, motivational gain (52) and anxiety reduction (53) have been considered to explain these positive health-coupled changes in the mind-brain body unit. However, for the present results anxiety reduction seems to be an unlikely explanation since - despite the fact that higher trait anxiety scores were associated with lower heat pain threshold scores - state anxiety difference scores were comparable in both treatment conditions.

Our behavioral data only allows for speculation about possible neural underpinnings. From a neurobiological point of view, the $\operatorname{PFC}(12,13)$ and its connectivity with the rest of the brain (54) has been repeatedly demonstrated to be of critical importance in the top-down, expectation-mediated model of adult placebo responses. In children, the PFC does not reach maturity and full connectivity until at least adolescence, and possibly not even until early adulthood $(16,17,55)$. Indeed, there are significant structural and functional differences between adults and children (16). Especially the increasing connectivity and changing balance between dynamic interacting later-maturing high association frontal lobe cortical networks (56) and earlier-maturing subcortical limbic systems in pediatrics. Moreover, patterns of cortical activation during cognitive tasks such as word generation (57), response inhibition (58) and selective attention (59) have been reported to be more diffuse in children and to rely more on subcortical brain network activation (60). Therefore, expectation-related PA in children suggests alternative - probably more subcortical neural pathways and processing strategies. As contrasted with a more cognitivelymediated PA in adults, one might speculate that in children, reward-related motivational, emotional appraisal (e.g. safety) and associated changes in intra- 
subcortical limbic-related circuitries (61), as well as attachment are critical for the mediation of PA.

\subsection{Gender-dependent differences in $P A$}

The PR for heat pain threshold was stronger for girls compared to boys as threshold difference scores increased more strongly between controls and the analgesiaexpectation group in girls than boys. The literature regarding gender difference of PR is sparse and equivocal (62), and analyses of gender-specific PR in the pediatric population have been especially neglected (8). Whereas some reviews failed to find differences (63) others have reported a slight placebo susceptibility advantage for girls in a migraine headache review (64). In the adult population, several factors such as differences in stress level, cortical processing styles, type of the placebo learning paradigm, hormonal influences, reporting biases, or the gender of the experimenter have been proposed as explanations for gender differences (62). Our results suggest mechanisms other than hormonal influences such as a possible slightly higher suggestibility for girls (65) (but see (66)), not attributable to differences in receptive language skills (66).

\subsection{MT modulates pain processing in boys, but not $P A$}

The findings both defy and confirm our original hypotheses. Against our prediction, PA was not influenced by MT. Previous findings (21) in healthy adults suggested a larger susceptibility for high MT participants. Several reasons may account for our failed replication. First, pronounced MT is a healthy property of a child's thinking (22, 23), and not an indicator of subclinical psychotic development (67). Therefore, quantitative and qualitative differences in youngsters' vs. adults' MT may hamper direct comparison with previous studies. Likewise, the fact that suggestibility is 
already extremely high at around 12 years of age (68) may have blurred hypothesized MT related suggestibility differences due to a ceiling effect. Lastly, differences in the type of pain stimuli and the absence of a control group without a placebo intervention in the study design of (21) might have produced these inconsistencies.

In line with our hypothesis, pain perception was asymmetrically modulated by MT. In the group with low MT, pain tolerance was higher for the right than the left forearm. Surprisingly no side difference was observed in the high MT group. This modulation is an exact replication of the pattern that has recently been reported in a similar study with healthy men (21). The result suggests an association between MT and a heightened right hemispheric activity already in children. A general bias towards right-hemisphere processing has long been described in infants and children (69), but our findings suggest that it may be modulated by gender as much as it is in adults (70). As gender-specific hormonal influences on dynamic functional laterality (71) and pain perception (72) is not a probable candidate to account for the interactions between laterality, MT and gender, future research is clearly needed to explore these fascinating, yet confusing interplay more thoroughly.

\subsection{Limitations, implications and future studies}

Undoubtedly, our study findings require replication in larger samples, and the underlying neural mechanisms of expectation-induced PA in relation to this dynamic nature of brain and cognitive-emotional development in children need to be unraveled. Of special interest would be the comparison between different cognitive and motivational neurodevelopment-related maturity and connectivity phases combined with a specific focus on the interaction between subcortical and prefrontal cortices. In addition, given that in our study heat pain threshold was difficult to assess 
reliably, more intuitive, real-time and non-verbal language measurement tools such as the recently proposed "pain mouse" (73) could be implemented in future pain assessment designs.

Clearly, the generalizability and potential implications to clinical practice of our data is limited since our study was designed to investigate the role of experimentally induced PA in acute and controllable thermal pain. Also, our present data does not enable a disentangling of differential components of the placebo intervention such as the narrative expectancy-induction, the disinfectant, its color and appearance or the warm relationship with the experimenter. Future studies may compare different types of verbal/nonverbal and conscious/unconscious suggestions (74) as well as the use other learning paradigms such as associative learning and learning by observation (75) and imitation.

In conclusion, the present study provides the first experimental evidence for a considerable expectation-related PA response on pain threshold and tolerance in healthy children. In addition, independent of analgesia expectations, MT modulated pain tolerance exclusively in male children. Overall this research suggests that context induced short-term analgesia beliefs and long-term MT beliefs independently modulate the experience of pain. These findings challenge the simple view of interpolating adult findings to the pediatric population. An improved understanding of the interaction between subjective belief and meaning systems, gender and agerelated neurodevelopmental phases in pain processing might have the potential to enhance therapeutic outcomes in children's individualized pain management. 


\section{References}

1. Colloca L, Miller FG. How placebo responses are formed: a learning perspective. Philos Trans R Soc Lond B Biol Sci. 2011;366:1859-69.

2. Colloca L, Klinger R, Flor H, Bingel U. Placebo analgesia: Psychological and neurobiological mechanisms. Pain. 2013;154:511-4.

3. Benedetti F. Placebo and the new physiology of the doctor-patient relationship. Physiol Rev. 2013;93:1207-46.

4. Benedetti F. Mechanisms of placebo and placebo-related effects across diseases and treatments. Annual Review of Pharmacology and Toxicology. 2008;48:33-60.

5. Kirsch I, Sapirstein G. Listening to Prozac but hearing placebo: a metaanalysis of antidepressant medication. Prevention \& Treatment. 1998;1(2):2a.

6. Parellada M, Moreno C, Moreno M, Espliego A, de Portugal E, Arango C. Placebo effect in child and adolescent psychiatric trials. Eur Neuropsychopharmacol. 2012;22:787-99.

7. Buck M. The placebo response in pediatric clinical trials. Pediatric Pharmacology. 2012;18.

8. Weimer K, Gulewitsch MD, Schlarb AA, Schwille-Kiuntke J, Klosterhalfen S, Enck P. Placebo effects in children: a review. Pediatr Res. 2013;74:96-102.

9. Abbott K, Fowler-Kerry S. The use of a topical refrigerant anesthetic to reduce injection pain in children. Journal of Pain and Symptom Management. 1995;10:584-90.

10. Arts SE, Abu-Saad HH, Champion GD, Crawford MR, Fisher RJ, Juniper KH, Ziegler JB. Age-related response to lidocaine-prilocaine (EMLA) emulsion and effect of music distraction on the pain of intravenous cannulation. Pediatrics. 1994;93:797-801.

11. Goodenough B, Kampel L, Champion GD, Laubreaux L, Nicholas MK, Ziegler $\mathrm{JB}$, Mclnerney M. An investigation of the placebo effect and age-related factors in the report of needle pain from venipuncture in children. Pain. 1997;72:383-91.

12. Krummenacher P, Candia V, Folkers G, Schedlowski M, Schönbächler G. Prefrontal cortex modulates placebo analgesia. Pain. 2010;148:368-74.

13. Benedetti F, Arduino C, Costa S, Vighetti S, Tarenzi L, Rainero I, Asteggiano G. Loss of expectation-related mechanisms in Alzheimer's disease makes analgesic therapies less effective. Pain. 2006;121:133-44.

14. Eippert F, Bingel U, Schoell ED, Yacubian J, Klinger R, Lorenz J, Buchel C. Activation of the opioidergic descending pain control system underlies placebo analgesia. Neuron. 2009;63:533-43.

15. Wager TD, Rilling JK, Smith EE, Sokolik A, Casey KL, Davidson RJ, Kosslyn $\mathrm{SM}$, Rose RM, Cohen JD. Placebo-induced changes in FMRI in the anticipation and experience of pain. Science. 2004;303:1162-7.

16. Giedd JN, Rapoport JL. Structural MRI of pediatric brain development: what have we learned and where are we going? Neuron. 2010;67:728-34.

17. Gogtay N, Giedd JN, Lusk L, Hayashi KM, Greenstein D, Vaituzis AC, Nugent TF, 3rd, Herman DH, Clasen LS, Toga AW, Rapoport JL, Thompson PM. Dynamic mapping of human cortical development during childhood through early adulthood. Proc Natl Acad Sci U S A. 2004;101:8174-9.

18. Scott DJ, Stohler CS, Egnatuk CM, Wang H, Koeppe RA, Zubieta JK. Individual differences in reward responding explain placebo-induced expectations and effects. Neuron. 2007;55:325-36. 
19. Schweinhardt P, Seminowicz DA, Jaeger E, Duncan GH, Bushnell MC. The anatomy of the mesolimbic reward system: a link between personality and the placebo analgesic response. J Neurosci. 2009;29:4882-7.

20. Krummenacher $\mathrm{P}$, Mohr $\mathrm{C}$, Haker $\mathrm{H}$, Brugger $\mathrm{P}$. Dopamine, paranormal belief, and the detection of meaningful stimuli. J Cogn Neurosci. 2010;22:1670-81.

21. Klemenz C, Regard M, Brugger P, Emch O. Laterality of pain: modulation by placebo and participants' paranormal belief. Cognitive and Behavioral Neurology. 2009;22:186-9.

22. Zusne L, Jones WH. Anomalistic psychology: A study of magical thinking. Hillsdale: Erlbaum; 1989 (2nd ed.).

23. Piaget JP. The child's conception of the world. London: Routledge \& Kegan Paul; 1929.

24. Brugger P. Tracking a finer madness. Scientific American Mind. 2007;10:77-9.

25. Folley BS, Park S. Verbal creativity and schizotypal personality in relation to prefrontal hemispheric laterality: a behavioral and near-infrared optical imaging study. Schizophr Res. 2005;80:271-82.

26. Mohr C, Bracha HS, Brugger P. Magical ideation modulates spatial behavior. The Journal of Neuropsychiatry and Clinical Neurosciences. 2003;15:168-74.

27. Coghill RC, Gilron I, ladarola MJ. Hemispheric lateralization of somatosensory processing. Journal of Neurophysiology. 2001;85:2602-12.

28. Symonds LL, Gordon NS, Bixby JC, Mande MM. Right-lateralized pain processing in the human cortex: an FMRI study. Journal of Neurophysiology. 2006;95:3823-30.

29. Oldfield RC. The assessment and analysis of handedness: the Edinburgh inventory. Neuropsychologia. 1971;9:97-113.

30. Grob A, Meyer CS, Hagmann-von Arx P. Intelligence and Development Scales (IDS). Bern: Hans Huber; 2009.

31. Bolton D, Dearsley P, Madronal-Luque R, Baron-Cohen S. Magical thinking in childhood and adolescence: Development and relation to obsessive compulsion. British Journal of Developmental Psychology. 2002;20:479-94.

32. Trapanotto M, Pozziani G, Perissinotto E, Barbieri S, Zacchello F, Benini F. The cold pressor test for the pediatric population: refinement of procedures, development of norms, and study of psychological variables. Journal of Pediatric Psychology. 2009;34:749-59.

33. Meier PM, Berde CB, DiCanzio J, Zurakowski D, Sethna NF. Quantitative assessment of cutaneous thermal and vibration sensation and thermal pain detection thresholds in healthy children and adolescents. Muscle \& Nerve. $2001 ; 24: 1339-45$.

34. Lu Q, Zeltzer LK, Tsao JC, Kim SC, Turk N, Naliboff BD. Heart rate mediation of sex differences in pain tolerance in children. Pain. 2005;118:185-93.

35. Wollgarten-Hadamek I, Hohmeister J, Zohsel K, Flor H, Hermann C. Do school-aged children with burn injuries during infancy show stress-induced activation of pain inhibitory mechanisms? Eur J Pain. 2011;15:423 e1-10.

36. Hicks CL, von Baeyer CL, Spafford PA, van Korlaar I, Goodenough B. The Faces Pain Scale-Revised: toward a common metric in pediatric pain measurement. Pain. 2001;93:173-83.

37. McGrath PA, Seifert CE, Speechley KN, Booth JC, Stitt L, Gibson MC. A new analogue scale for assessing children's pain: an initial validation study. Pain. 1996;64:435-43.

38. Vase L, Riley JL, 3rd, Price DD. A comparison of placebo effects in clinical analgesic trials versus studies of placebo analgesia. Pain. 2002;99:443-52. 
39. Kaptchuk TJ, Kelley JM, Conboy LA, Davis RB, Kerr CE, Jacobson EE, Kirsch I, Schyner RN, Nam BH, Nguyen LT, Park M, Rivers AL, McManus C, Kokkotou E, Drossman DA, Goldman P, Lembo AJ. Components of placebo effect: randomised controlled trial in patients with irritable bowel syndrome. Bmj. 2008;336:999-1003.

40. Kelley JM, Lembo AJ, Ablon JS, Villanueva JJ, Conboy LA, Levy R, Marci CD, Kerr CE, Kirsch I, Jacobson EE, Riess H, Kaptchuk TJ. Patient and practitioner influences on the placebo effect in irritable bowel syndrome. Psychosom Med. 2009;71:789-97.

41. Spielberger CD. STAIC. Preliminary manual for the state-trait anxiety inventory for children. Palo Alto, CA: Consulting Psychologists Press; 1973.

42. IBM, Corp. IBM SPSS Statistics for Mac. Version 21.0. Armonk. 21.0 ed. NY: IBM Corp; 2012.

43. Page RA, Green JP. An update on age, hypnotic suggestibility, and gender: a brief report. Am J Clin Hypn. 2007;49:283-7.

44. Morgan $\mathrm{AH}$, Ernest $\mathrm{RH}$. Age differences in susceptibility to hypnosis. International Journal of Clinical and Experimental Hypnosis. 1973;21:78-85.

45. Colloca L, Sigaudo M, Benedetti F. The role of learning in nocebo and placebo effects. Pain. 2008;136:211-8.

46. Parellada M, Moreno C, Moreno M, Espliego A, de Portugal E, Arango C. Placebo effect in child and adolescent psychiatric trials. Eur Neuropsychopharmacol. 2011.

47. Kut E, Schaffner N, Wittwer A, Candia V, Brockmann M, Storck C, Folkers G. Changes in self-perceived role identity modulate pain perception. Pain. 2007;131:191-201.

48. Lidstone SC, Schulzer M, Dinelle K, Mak E, Sossi V, Ruth TJ, de la FuenteFernandez R, Phillips AG, Stoessl AJ. Effects of expectation on placeboinduced dopamine release in Parkinson disease. Arch Gen Psychiatry. 2010;67:857-65.

49. de la Fuente-Fernandez R, Ruth TJ, Sossi V, Schulzer M, Calne DB, Stoessl AJ. Expectation and dopamine release: mechanism of the placebo effect in Parkinson's disease. Science. 2001;293:1164-6.

50. Benedetti F, Thoen W, Blanchard C, Vighetti S, Arduino C. Pain as a reward: changing the meaning of pain from negative to positive co-activates opioid and cannabinoid systems. Pain. 2013;154:361-7.

51. Stewart-Williams S, Podd J. The placebo effect: dissolving the expectancy versus conditioning debate. Psychol Bull. 2004;130:324-40.

52. Price DD, Finniss DG, Benedetti F. A comprehensive review of the placebo effect: recent advances and current thought. Annu Rev Psychol. 2008;59:56590.

53. Petrovic P, Dietrich T, Fransson P, Andersson J, Carlsson K, Ingvar M. Placebo in emotional processing--induced expectations of anxiety relief activate a generalized modulatory network. Neuron. 2005;46:957-69.

54. Stein N, Sprenger C, Scholz J, Wiech K, Bingel U. White matter integrity of the descending pain modulatory system is associated with interindividual differences in placebo analgesia. Pain. 2012;153:2210-7.

55. Casey BJ, Tottenham N, Liston C, Durston S. Imaging the developing brain: what have we learned about cognitive development? Trends Cogn Sci. 2005;9:104-10.

56. Casey BJ, Duhoux S, Malter Cohen M. Adolescence: what do transmission, transition, and translation have to do with it? Neuron. 2010;67:749-60. 
57. Brown TT, Lugar HM, Coalson RS, Miezin FM, Petersen SE, Schlaggar BL. Developmental changes in human cerebral functional organization for word generation. Cerebral Cortex. 2005;15:275-90.

58. Casey BJ, Castellanos FX, Giedd JN, Marsh WL, Hamburger SD, Schubert AB, Vauss YC, Vaituzis AC, Dickstein DP, Sarfatti SE, Rapoport JL. Implication of right frontostriatal circuitry in response inhibition and attentiondeficit/hyperactivity disorder. Journal of the American Academy of Child and Adolescent Psychiatry. 1997;36:374-83.

59. Booth JR, Burman DD, Meyer JR, Trommer BL, Davenport ND, Parrish TB, Gitelman DR, Mesulam MM. Brain-behavior correlation in children depends on the neurocognitive network. Hum Brain Mapp. 2004;23:99-108.

60. Luna B, Thulborn KR, Munoz DP, Merriam EP, Garver KE, Minshew NJ, Keshavan MS, Genovese CR, Eddy WF, Sweeney JA. Maturation of widely distributed brain function subserves cognitive development. Neuroimage. 2001;13:786-93.

61. Wager TD, Atlas LY, Leotti LA, Rilling JK. Predicting individual differences in placebo analgesia: contributions of brain activity during anticipation and pain experience. J Neurosci. 2011;31:439-52.

62. Enck P, Benedetti F, Schedlowski M. New insights into the placebo and nocebo responses. Neuron. 2008;59:195-206.

63. Evers S, Marziniak M, Frese A, Gralow I. Placebo efficacy in childhood and adolescence migraine: an analysis of double-blind and placebo-controlled studies. Cephalalgia. 2009;29:436-44.

64. Lewis DW, Kellstein D, Dahl G, Burke B, Frank LM, Toor S, Northam RS, White LW, Lawson L. Children's ibuprofen suspension for the acute treatment of pediatric migraine. Headache. 2002;42:780-6.

65. Messerschmidt R. The Suggestibility of Boys and Girls Between the Ages of Six and Sixteen Years. The Pedagogical Seminary and Journal of Genetic Psychology. 1933;43:422-37.

66. Bruck M, Melnyk L. Individual Differences in Children's Suggestibility: A Review and Synthesis. Appl Cognit Psychol. 2004;18:947-96.

67. Eckblad M, Chapman LJ. Magical ideation as an indicator of schizotypy. J Consult Clin Psychol. 1983;51:215-25.

68. Bauman DE, Bul PI. [Human inheritability of hypnotizability]. Genetika. 1981;17:352-6.

69. Chiron C, Jambaque I, Nabbout R, Lounes R, Syrota A, Dulac O. The right brain hemisphere is dominant in human infants. Brain. 1997;120 ( Pt 6):105765.

70. Brugger P, Graves RE. Right hemispatial inattention and magical ideation. European Archives of Psychiatry and Clinical Neuroscience. 1997;247:55-7.

71. Rode C, Wagner M, Gunturkun O. Menstrual cycle affects functional cerebral asymmetries. Neuropsychologia. 1995;33:855-65.

72. Sherman JJ, LeResche L. Does experimental pain response vary across the menstrual cycle? A methodological review. Am J Physiol Regul Integr Comp Physiol. 2006;291:R245-56.

73. Schaffner N, Folkers G, Kappeli S, Musholt M, Hofbauer GF, Candia V. A new tool for real-time pain assessment in experimental and clinical environments. PLoS One. 2012;7:e51014.

74. Jensen KB, Kaptchuk TJ, Kirsch I, Raicek J, Lindstrom KM, Berna C, Gollub $\mathrm{RL}$, Ingvar M, Kong J. Nonconscious activation of placebo and nocebo pain responses. Proc Natl Acad Sci U S A. 2012;109:15959-64. 
Krummenacher et al., 2014

75. Colloca L, Benedetti F. Placebo analgesia induced by social observational learning. Pain. 2009;144:28-34. 


\section{Figure Captions}

Fig. 1. Experimental design. Half of the children were either randomly - stratified for magical thinking (MT) and gender - assigned to the analgesia-expectation ("blue hand disinfectant as painkiller", upper panel) or a control-expectation condition ("blue hand disinfectant as measurement facilitator", lower panel). Children' heat pain tolerance and threshold as well as subjective pain judgments by means of FPS-R (Faces Pain Scale-Revised) and FAS (Facial Affective Scale) were measured on both volar forearms (counterbalanced and homologous site) at baseline and after the expectation induction procedure. Participants' state anxiety was assessed prior to each of the two pain measurements. Trait anxiety was judged at the end of the experiment.

Fig. 2: Difference score (treatment condition - baseline condition) of heat pain threshold (mean \pm SEM) for girls (white bars) and boys (grey bars) in both expectation conditions ("control-expectation" or "analgesia-expectation"). Baseline level $=0$; placebo analgesia $=$ positive values. Asterisks $\left({ }^{*},{ }^{* *},{ }^{* * *}\right)$ indicate significant post-hoc and baseline comparisons $\left({ }^{*} p<0.05 ;{ }^{* *} p<0.01 ;{ }^{* * *} p<0.001\right)$. Data are averaged over MT group (low and high MT) and side of pain application (left and right forearm).

Fig. 3: Difference score (treatment condition - baseline condition) of heat pain threshold (mean \pm SEM) for both MT groups ("low MT" or "high MT") in girls (white bars) and boys (grey bars). Baseline level $=0$; placebo analgesia $=$ positive values Asterisks $\left({ }^{*},{ }^{* *},{ }^{* * *}\right)$ indicate significant post-hoc and baseline comparisons $\left({ }^{*} p<0.05\right.$; ${ }^{* *} p<0.01 ;{ }^{* *} p<0.001$ ). Data are averaged over expectation condition (control- 
expectation and analgesia-expectation) and side of pain application (left and right forearm).

Fig. 4: Difference score (treatment condition - baseline condition) of heat pain tolerance (mean \pm SEM) for left (white bars) and right (grey bars) forearm heat pain stimulation in both expectation conditions ("control-expectation" or "analgesiaexpectation"). Baseline level $=0$; placebo analgesia $=$ positive values. Asterisks $\left({ }^{*},{ }^{* *},{ }^{* *}\right)$ indicate significant post-hoc and baseline comparisons $\left({ }^{*} p<0.05 ;{ }^{* *} p<\right.$ $0.01 ;{ }^{* * *} p<0.001$ ). Data are averaged over MT group (low and high MT) and gender (girls and boys).

Fig. 5: Difference score (treatment condition - baseline condition) of heat pain tolerance (mean \pm SEM) for left (white bars) and right (grey bars) forearm heat pain stimulation in both MT groups ("low MT" or "high MT") (A) and separated for girls (B) and boys $(\mathrm{C})$. Baseline level $=0$; placebo analgesia $=$ positive values. Asterisks $\left({ }^{* * *},{ }^{* * *}\right)$ indicate significant post-hoc and baseline comparisons $\left({ }^{*} p<0.05 ;{ }^{* *} p<\right.$ $\left.0.01 ;{ }^{* * *} \mathrm{p}<0.001\right)$. Data are averaged over expectation condition (controlexpectation and analgesia-expectation) and gender (girls and boys) (A) and only over expectation condition (control-expectation and analgesia-expectation) (B, C). 
Krummenacher et al., 2014

\section{Table Legend}

Table 1: Descriptive data of the study sample.

Data (Means (SD)) correspond to the two treatment conditions (analgesiaexpectation or control-expectation) and the four corresponding subgroups (low and high magical thinking in boys and girls). 